\title{
Peeling Back the Layers: Complex Dynamics Shaping the Evolution of the Ledebouriinae
} (Scilloideae, Asparagaceae)

(1)

\author{
Cody Coyotee Howard ${ }^{1,2, *}$, Andrew A. Crowl ${ }^{3}$, Timothy S. HARVEY ${ }^{4}$, AND Nico \\ CELLINESE ${ }^{1,5,6}$ \\ ${ }^{1}$ Florida Museum of Natural History, University of Florida, Gainesville, FL 32611, USA \\ ${ }^{2}$ Department of Biology, University of Florida, Gainesville, FL 32611, USA \\ ${ }^{3}$ Duke University, Durham, NC 27708, USA \\ ${ }^{4}$ Plantae Novae, Thousand Oaks, CA 91360, USA \\ ${ }^{5}$ Biodiversity Institute, University of Florida, Gainesville, FL 32611, USA \\ ${ }^{6}$ Genetics Institute, University of Florida, Gainesville, FL 32611, USA
}

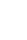

* Correspondence to be sent to: Cody Coyotee Howard, Department of Biology, University of Florida, Gainesville, FL 32611, USA; Email: cchoward@ufl.edu

Abstract - The Ledebouriinae (Scilloideae, Asparagaceae) are a widespread group of bulbous geophytes found predominantly throughout seasonal climates in sub-Saharan Africa, with a handful of taxa in Madagascar, the Middle East, India, and Sri Lanka. Phylogenetic relationships within the group have been historically difficult to elucidate. Here, we provide the first phylogenomic perspective into the Ledebouriinae. Using the Angiosperms353 targeted enrichment probe set, we consistently recovered four major clades (i.e., two Ledebouria clades, Drimiopsis, and Resnova). The two Ledebouria clades closely align with geography, either 


\section{Howard, et al.}

consisting almost entirely of sub-Saharan African taxa (Ledebouria Clade A), or East African and non-African taxa (Ledebouria Clade B). Our results suggest that the Ledebouriinae likely underwent a rapid radiation leading to rampant incomplete lineage sorting. We additionally find evidence for potential ancient hybridization between Drimiopsis and a subclade within Ledebouria Clade A. [Asparagaceae; Drimiopsis; geophytes; Ledebouria; monocots; Resnova; Scilloideae.]

(1)

(1)

Africa houses an enormous diversity of plants found across a range of habitats from tropical rainforests to arid landscapes (Linder 2014; Couvreur et al. 2020). Still, there remain numerous, understudied African taxa that may advance our ability to refine hypotheses regarding evolution within Africa (e.g., the Rand Flora (Pokorny et al. 2015), the "arid track" (Balinsky 1962)), or showcase their own distinct patterns. One such group is the hyacinths (Scilloideae, Asparagaceae; formerly Hyacinthaceae; APG IV (The Angiosperm Phylogeny Group 2016)), which consist of approximately 1,000 bulbous geophytes found throughout seasonal climates in Africa, as well as Madagascar, Europe, the Middle East, India, Sri Lanka, and South America (Speta 1998). Digging into the evolution of the Scilloideae has improved our understanding of historical biogeography in Africa (Buerki et al. 2012; Ali et al. 2013), polyploidy (Jang et al. 2018), and ecology (Johnson et al. 2001; Vogel and Müller-Doblies 2011). Unfortunately, the group remains largely understudied. To date, many clades within the Scilloideae have received varying degrees of phylogenetic and systematic attention (e.g., Ledebouriinae, Massonieae, Ornithogaloideae; (Pfosser et al. 2003; Lebatha et al. 2006; Martínez-Azorín et al. 2011); among many others), but phylogenomic applications are almost nonexistent (Steele et al. 2012). To showcase the value of focusing attention on understudied groups such as the Scilloideae, we 


\section{DYNAMICS SHAPING THE EVOLUTION OF THE LEDEBOURIINAE}

47 investigate the phylogenomic space of one of its subclades - the Ledebouriinae- the

48 evolutionary relationships of which have been historically difficult to reconstruct.

The Ledebouriinae are widespread across sub-Saharan Africa, found predominantly

50 within the "arid track" (Balinsky 1962), with just a handful of taxa in Madagascar, Yemen, India and Sri Lanka (Fig. 1a; (Venter 1993; Giranje and Nandikar 2016). The current center of

53 1993), with a secondary center in East Africa (Lebatha 2004; Lebatha et al. 2006).

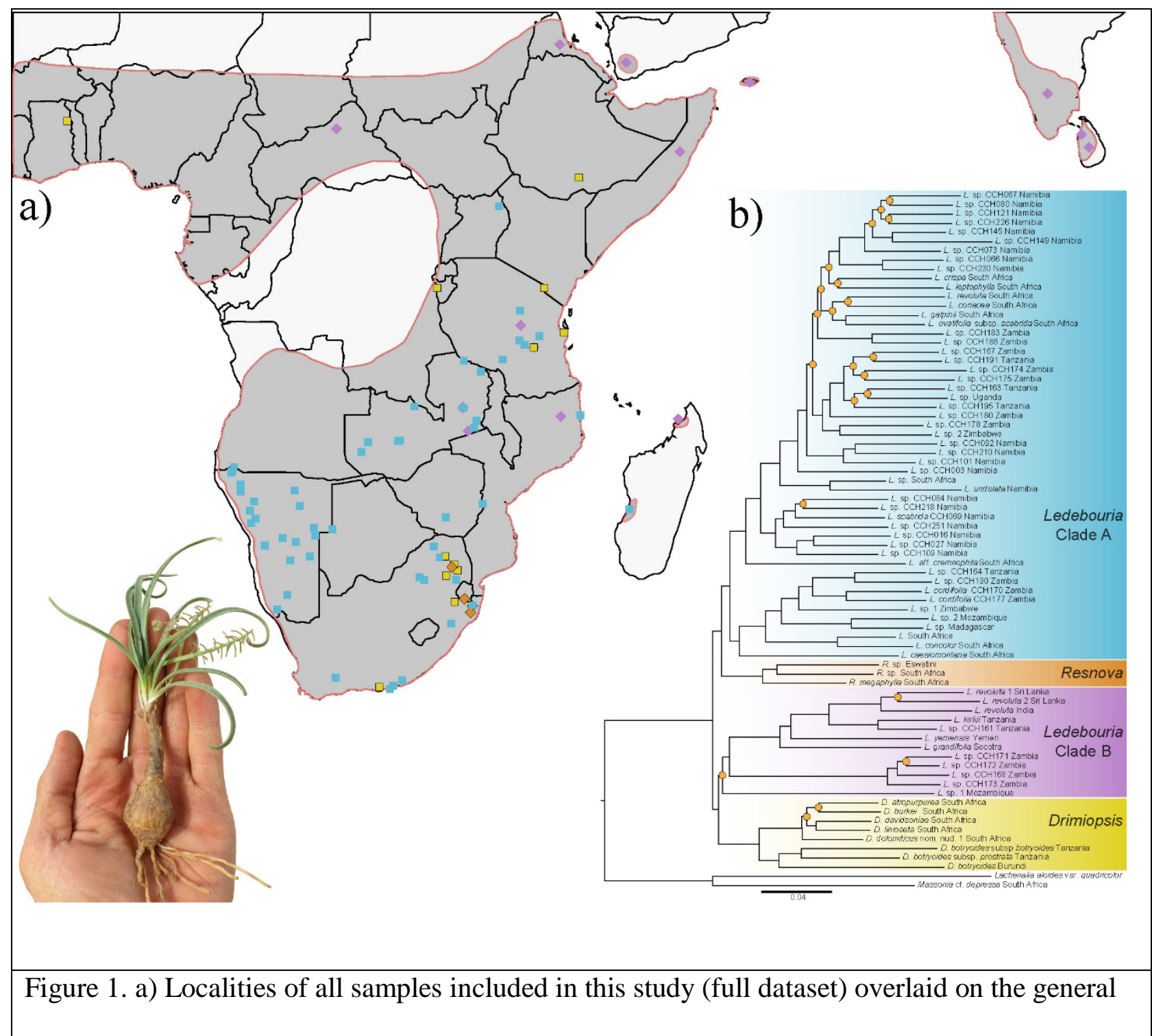




\section{Howard, et al.}

distribution of the Ledebouriinae (dark gray polygon). Shapes and colors correspond to clades shown in (b): Ledebouria Clade A (blue squares), Ledebouria clade B (purple diamonds), Resnova (outlined orange diamonds), Drimiopsis (outlined yellow squares). b) Maximum likelihood phylogenetic reconstruction of the Taxa70 dataset with the four major clades labeled. Orange circles indicate nodes with SH-aLRT and ultrafast bootstrap values below 80 and 95 , respectively.

Taxonomically, the group currently consists of Ledebouria Roth with two sections: Drimiopsis whether this group includes one or more distinct entities (Manning et al. 2003; Lebatha et al. 2006). Historically, Ledebouria and Drimiopsis Lindl. \& Paxton were classified as separate taxa, and Drimiopsis enjoyed its own identity for some time (Lebatha et al. 2006; Müller-Doblies and Müller-Doblies 2008; Goldblatt et al. 2012). The status of Resnova van der Merwe, on the other hand, has always been in question (Manning et al. 2003; Lebatha et al. 2006; Goldblatt et al. 2012; Manning 2020). There are currently 53 Ledebouria, 16 Drimiopsis, and five Resnova 65 species accepted (The Plant List 2013), with the majority of systematic work occurring in South Africa (Venter 1993). Thus far, difficulties in reconstructing the phylogenetic history of the

67 Ledebouriinae have stemmed from morphological homoplasy (Lebatha et al. 2006), the use of a small number of molecular markers with low information content (Manning et al. 2003), the lack of robust phylogenetic methods (Pfosser et al. 2003; Wetschnig et al. 2007), and the inclusion of 


\section{DYNAMICS SHAPING THE EVOLUTION OF THE LEDEBOURIINAE}

71 constrain our ability to detect confounding factors that have likely impacted the evolutionary

72 history of the Ledebouriinae, which may be why it has been difficult to confidently reconstruct

73 it.

$74 \quad$ Based on previous dating analyses (Ali et al. 2012; Buerki et al. 2012), we hypothesize

75 that the Ledebouriinae have experienced a rapid radiation(s). These studies suggest that the

76 group originated during a time (i.e., within the last $30 \mathrm{My}$ ) when Africa was undergoing major

77 climatic and geological shifts (e.g., increasing seasonality, orogenic activity) (Partridge and

78 Maud 1987; Jacobs 2004; Bobe 2006), and the bulbous geophytic habit may have allowed the

79 Ledebouriinae to capitalize on such conditions (Howard et al. 2019). Additionally, hybridization

80 and polyploidy within and between groups has been documented (Stedje and Nordal 1987;

81 Lebatha et al. 2006), which present further complications in reconstructing the evolutionary

82 history of the group. Therefore, to recover a well-supported phylogenetic hypothesis for the

83 Ledebouriinae, the use of a large, genomic dataset consisting of rapidly evolving markers is

84 likely needed. Unfortunately, the group lacks the necessary genomic resources to develop a

85 custom probe set. However, broadly applicable targeted-capture kits (Johnson et al. 2019;

86 Breinholt et al. 2021) have been instrumental in bringing understudied groups, like the

87 Ledebouriinae, to the phylogenomic playing field (Dodsworth et al. 2019).

Here, we apply a HybSeq/targeted enrichment approach using the Angiosperms 353 probe

89 set, which has been effective in uncovering relationships at both deep and shallow scales

90 (Larridon et al. 2019). The use of this probe set circumvents the lack of genomic resources that

91 plagues the Ledebouriinae and allows future studies to leverage our dataset, which will enable

92 continual refinement of the phylogenetic understanding of this group as well as the Scilloideae.

93 We include samples from across the distribution of the group using both field-collected and 


\section{Howard, et al.}

94 museum-based specimens to investigate putative lineages within the Ledebouriinae (i.e.,

95 Ledebouria, Drimiopsis and Resnova) as well as potential reasons for discordance.

96

97

98

\section{9}

100

101

102

103

104

105

106

107

108

109

110

MATERIALS AND Methods

\section{Taxon Sampling and Sequence Assembly}

Plants of Ledebouriinae were collected from the field in 2012 (Namibia), 2014

(Namibia), and 2017 (Tanzania, Zambia, and Namibia). Leaves of each sample were dried in silica gel for DNA extractions. Herbarium material from four institutions (Missouri Botanical

Gardens, Uppsala's Evolutionsmuseet Botanik, Sweden Museum of Natural History, and The Royal Botanic Gardens, Kew, DNA Bank, https://www.kew.org/data/dnaBank/) were also included. Additionally, silica-dried leaf material from specimens with known provenance were generously donated from private collections. Our final dataset included 94 Ledebouriinae samples from across the distribution of the group as well as two outgroup taxa (Massonia cf. depressa Houtt. and Lachenalia aloides var. quadricolor (Jacq.) Engl.). See Supplementary

Table 1 for the specimen list with associated collection and locality information. Targeted capture was performed using the Angiosperms353 probe set on an Illumina HiSeq 2000 followed by sequence assembly and alignment.

\section{Phylogenetic Analyses}

We constructed two datasets composed of supercontig sequences (i.e., consensus sequences for each targeted locus including intronic and exonic regions). The full dataset included all samples regardless of missing data. The second dataset included taxa with less than $70 \%$ missing data in the supermatrix alignment (i.e., <=70\% gaps/ambiguities; referred to as Taxa70). Maximum likelihood phylogenetic reconstruction was performed using IQ-Tree v2.0rc1 (Minh et al. 2020). We quantified discordance and concordance using 1) gene concordance 


\section{DYNAMICS SHAPING THE EVOLUTION OF THE LEDEBOURIINAE}

117 factors (gCF; percentage of genes supporting the input topology) and site concordance factors

118 (sCF; percentage of sites informative for a branch) as implemented in IQ-Tree v2.0-rc1, and 2)

119 Quartet Sampling (QS), which provides unique and more revealing information pertaining to

120 discordance often prevalent in phylogenomic datasets (Pease et al. 2018). We further quantified

121 gene tree discordance within the Taxa70 dataset using DiscoVista (Sayyari et al. 2018). To

122 obtain a species tree while also accounting for potential instances of incomplete lineage sorting,

123 we used ASTRAL III v5.6.2 (Zhang et al. 2018) as well as singular value decomposition quartet

124 species-tree estimation (SVDQuartets) (Chifman and Kubatko 2014) implemented in PAUP*

125 v4.0a (Swofford 2001). Lastly, we investigated potential instances of hybridization on randomly

126 subsampled phylogenies of ten taxa using SNaQ (Solís-Lemus et al. 2017). See Supplementary

127 Methods for an expanded explanation of methodology.

RESULTS

Excluding the full dataset, which included samples with large amounts of missing data,

130 the major clades received overall high support according to SH-aLRT, ultrafast bootstrap

131 (UFBoot), and local posterior probability (LPP) (Table 1, Fig. 2, Supplementary Figs. 1 - 4). 
Howard, et al.

\begin{tabular}{|c|c|c|c|c|c|c|c|}
\hline & Dataset & Ledebouria Clade A + Resnova & Ledebouria Clade A & Resnova & Ledebouria Clade B + Drimiopsis & Ledebouria Clade B & Drimiopsis \\
\hline \multirow[t]{3}{*}{ UFBoot } & Full & 97 & 90 & 100 & 93 & 76 & 100 \\
\hline & Taxa70 & 100 & 100 & 100 & 95 & 70 & 100 \\
\hline & L. sp. 1 Moz removed & 100 & 100 & 100 & 100 & 97.2 & 100 \\
\hline \multirow[t]{3}{*}{$\overline{\text { SH-aLRT }}$} & Full & 100 & 97.7 & 100 & 98.9 & 15.9 & 100 \\
\hline & Taxa70 & 100 & 99 & 100 & 99.6 & 14.3 & 100 \\
\hline & L. sp. 1 Moz removed & 100 & 98.8 & 100 & 100 & 100 & 100 \\
\hline \multirow[t]{3}{*}{ LPP } & Full & 1 & 0.97 & 0.34 & 0.91 & 0.62 & 1 \\
\hline & Taxa 70 & 1 & 0.95 & 1 & 0.96 & 0.74 & 1 \\
\hline & L. sp. 1 Moz removed & 1 & 0.93 & 1 & 0.98 & 1 & 1 \\
\hline \multirow[t]{3}{*}{ gCF } & Full & 3.67 & 2.56 & 44.2 & 3.57 & 2.78 & 26.8 \\
\hline & Taxa70 & 4.67 & 2.56 & 46.6 & 4.87 & 3.47 & 32.7 \\
\hline & L. sp. 1 Moz removed & 5.67 & 2.56 & 47 & 4.55 & 16 & 34 \\
\hline \multirow[t]{3}{*}{ sCF } & Full & 38.8 & 34.3 & 59.7 & 32.4 & 36.1 & 44.8 \\
\hline & Taxa70 & 40 & 37.7 & 65.1 & 34.3 & 36.5 & 55.5 \\
\hline & L. sp. 1 Moz removed & 39.5 & 38 & 64.3 & 33.9 & 38.5 & 54.1 \\
\hline \multirow[t]{3}{*}{ QC } & Full & 0.035 & 0.031 & 0.32 & 0.019 & -0.017 & 0.37 \\
\hline & Taxa70 & -0.0045 & 0.025 & 0.33 & 0.0081 & 0.031 & 0.27 \\
\hline & L. sp. $1 \mathrm{Moz}$ removed & 0.05 & 0.023 & 0.39 & 0.047 & 0.026 & 0.33 \\
\hline \multirow[t]{3}{*}{ QD } & Full & 0.81 & 0.76 & 0.95 & 0.92 & 0.77 & 0.47 \\
\hline & Taxa70 & 0.88 & 0.83 & 0.77 & 0.86 & 0.85 & 0.55 \\
\hline & L. sp. $1 \mathrm{Moz}$ removed & 0.74 & 1 & 0.92 & 0.86 & 0.98 & 0.43 \\
\hline \multirow[t]{3}{*}{ QI } & Full & 0.34 & 0.41 & 0.54 & 0.3 & 0.33 & 0.48 \\
\hline & Taxa70 & 0.33 & 0.38 & 0.58 & 0.31 & 0.31 & 0.5 \\
\hline & L. sp. $1 \mathrm{Moz}$ removed & 0.34 & 0.39 & 0.57 & 0.27 & 0.32 & 0.55 \\
\hline
\end{tabular}

Table 1. Support value measures, gene concordance factor ( $\mathrm{gCF})$, site concordance factor (sCF), and quartet sampling measures for the four major clades recovered. Full shows values for the full dataset, Taxa70 reports values for the Taxa70 dataset, and L. sp. 1 Moz removed shows values when Ledebouria sp. 1 Mozambique is removed from the analyses. Support measures are ultrafast bootstrap (UFBoot), SH-like approximate likelihood ratio test (SH-aLRT), and local posterior probability (LPP). Support measures are those recovered using the GENESITE partition resampling measure in IQ-Tree. Gene concordance factor $(\mathrm{gCF})$ is expressed as the percentage of genes that support a given topology, site concordance factor ( $\mathrm{sCF}$ ) is expressed as the number of sites informative for a branch. Quartet sampling measures include quartet concordance (QC), quartet differential (QD), and quartet informativeness (QI). See Supplementary Methods or Pease et al. (2018) for a detailed explanation of these measures. 


\section{DYNAMICS SHAPING THE EVOLUTION OF THE LEDEBOURIINAE}

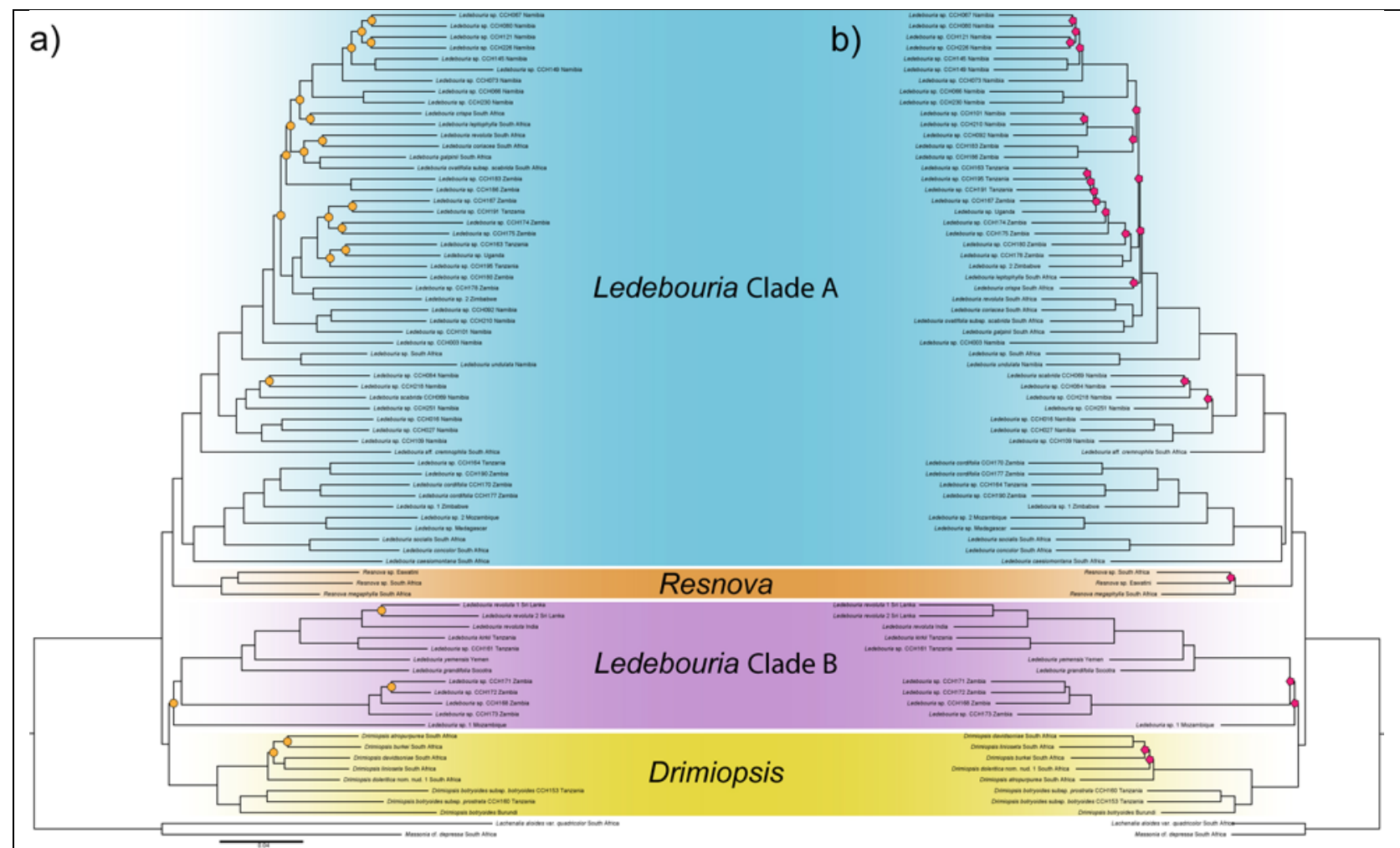

Figure 2. Phylogenetic reconstruction of the Taxa70 datasets using maximum likelihood as implemented in IQ-Tree (a), and species tree estimation as implemented in ASTRAL III (b). a) Orange circles indicate nodes with SH-aLRT and ultrafast bootstrap values below 80 and 95 , respectively. b) Pink polygons indicate nodes with local posterior probability (LPP) below .95. Note, the same four major clades are recovered in both, with differences in relationships of subclades and tips between the two analyses, particularly within Ledebouria Clade A.

Our analyses consistently recovered a paraphyletic Ledebouria, with each Ledebouria clade sister to either Resnova or Drimiopsis (Fig. 2). However, two results warrant attention. First, in the full dataset, we found a paraphyletic Resnova (Supplementary Fig. 1) and recovered low LPP for Resnova (Supplementary Fig. 2). After the removal of one herbarium sample found in only four alignments (i.e., Resnova lachenalioides, which was a sample that consistently jumped

137 around potentially due to missing data [compare Supplementary Figs. 1, 2, 9]), we found 
Howard, et al.

138 increased support for a monophyletic Resnova across all measures (Table 1, Fig. 2,

139 Supplementary Figs. 3, 4). Second, Drimiopsis + Ledebouria Clade B recovered overall high

140 support except in the full dataset (Table 1, Supplementary Figs. 1, 2). Using all samples, we

141 found low support for Ledebouria Clade B in terms of the placement of Ledebouria sp. 1

142 Mozambique (Fig. 2, Table 1, Supplementary Figs. 1, 2). The subclade sister to this sample

143 shows higher but still low support in the full dataset (Fig. 2, Supplementary Figs. 1, 2). In the

144 Taxa70 dataset, we find stronger support for Drimiopsis + Ledebouria Clade B (Supplementary

145 Figs. 3, 4). Support increases further for Drimiopsis + Ledebouria Clade B as well as Ledebouria

146 Clade B alone after the removal of Ledebouria sp. 1 Mozambique (Table 1, Supplementary Figs.

$1475,6)$.

148 We found relatively low gene ( $\mathrm{gCF}$ ) and site ( $\mathrm{sCF}$ ) concordance factors for many nodes

149 in both the full and Taxa70 datasets (Table 1; Supplementary Figs. 1, 3). Quartet concordance

150 values were mostly positive for the four major clades (Table 1; Supplementary Figs. 7, 8).

151 Quartet differential (QD) indicated low proportions of an alternative evolutionary history (i.e.,

152 values nearer to 1) (Table 1; Supplementary Figs. 7, 8). Quartet informativeness (QI) indicated

153 low informativeness of the quartets for the topology, reflecting the results of sCF (Table 1;

154 Supplementary Figs. 7, 8). DiscoVista reported only one gene tree that supports a monophyletic

155 Ledebouria (Fig. 3b; Supplementary Table 2). 


\section{DYNAMICS SHAPING THE EVOLUTION OF THE LEDEBOURIINAE}
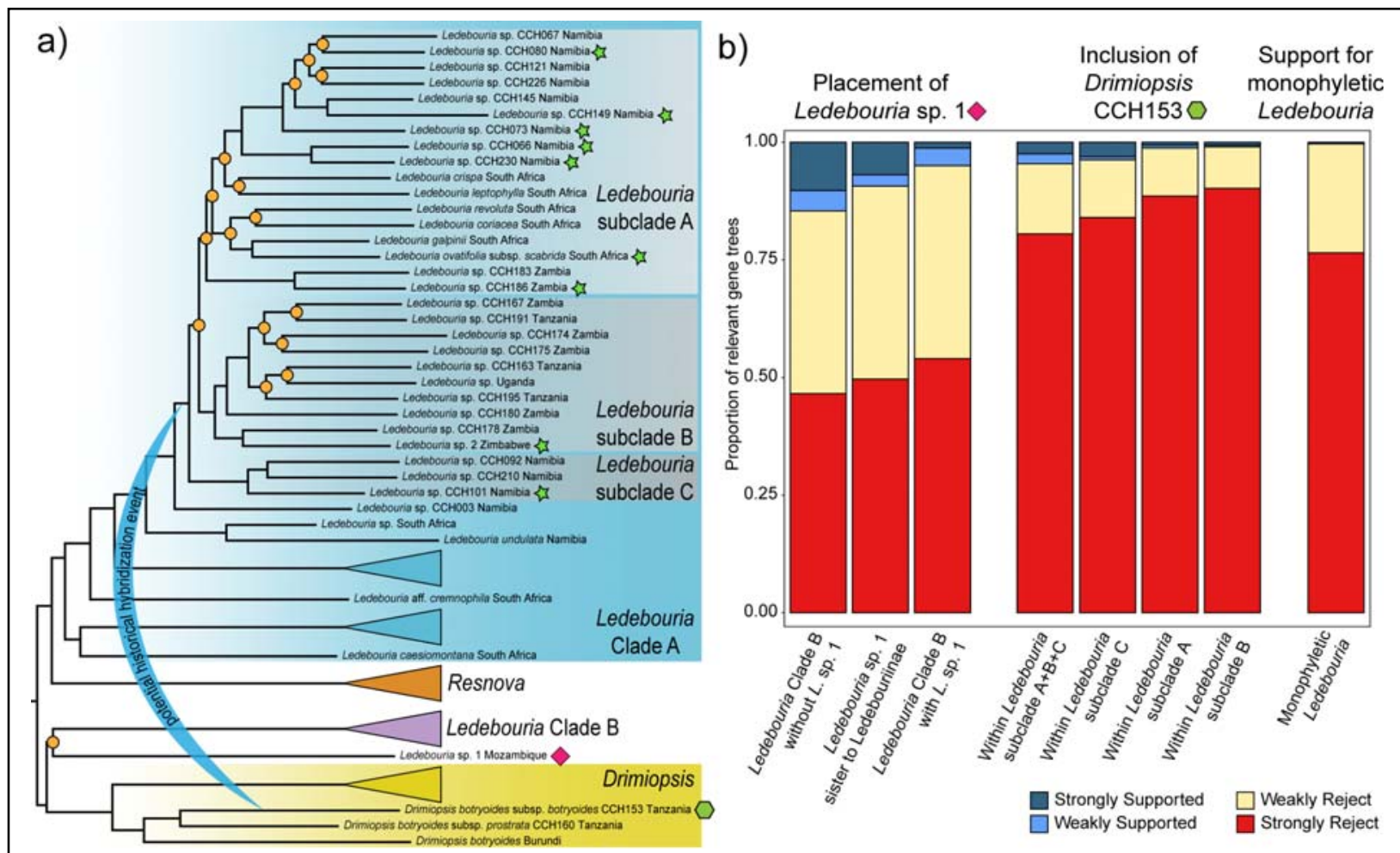

Figure 3. Summary of hypothesized hybridization and phylogenetic discordance. a)

Maximum likelihood reconstruction with select clades collapsed for clarity; see Fig. 1 for the full Taxa70 phylogeny. Green stars indicate taxa identified as potentially involved in a hybridization event with Drimiopsis botryoides subsp. botryoides $\mathrm{CCH} 153$ [green polygon] in randomly subsampled replicate analyses. Given these results, we hypothesize an ancient hybridization event involving an ancestor of this subclade. Orange circles indicate nodes with SH-aLRT and ultrafast bootstrap values below 80 and 95, respectively. b) The number of relevant gene trees (i.e., those with the clade(s) of interest) that support or reject clades of interest. The first three bars show the number of gene trees that support the placement of Ledebouria sp. 1 Mozambique [phylogenetic placement marked by a pink diamond in a] in relation to Ledebouria Clade B and the Ledebouriinae. The middle four bars show the number of genes that support the placement of Drimiopsis botryoides subsp. botryoides CCH153 within the subclade of Ledebouria Clade A where an ancient hybridization event may have occurred. The last bar shows the number of gene trees that support a monophyletic Ledebouria. 


\section{Howard, et al.}

157 A surprisingly high number of gene trees placed Drimiopsis botryoides subsp. botryoides

158 CCH153 within a subclade of Ledebouria Clade A (Fig. 3b; Supplementary Table 2). The

159 DiscoVista results complement the results from $\mathrm{SNaQ}$, which placed a potential hybridization

160 event between the same Drimiopsis sample and several taxa within Ledebouria Clade A (Fig. 3a;

161 Supplementary Fig. 12). Interestingly, this Ledebouria subclade also has the lowest supported

162 nodes within the entire phylogeny (Fig. 2, 3a).

For both the full dataset and Taxa70 dataset, SVDQuartets returned the same overall

results as IQ-Tree and ASTRAL with a few notable exceptions (Supplementary Figs. 9 - 12).

165

166

167

168

169

170

171

172

173

174

175

176

177

178

179

Low bootstrap values were found across the full dataset phylogeny, and Resnova lachenalioides

was placed within Ledebouria Clade B (Supplementary Fig. 9, 10). In both datasets,

SVDQuartets placed Ledebouria sp. 1 Mozambique sister to the remaining Ledebouriinae

(Supplemental Figs. 9 - 12). This complements the results from DiscoVista, which reported more gene trees supporting Ledebouria sp. 1 Mozambique as sister to the Ledebouriinae than those that included it within the clade (Fig. 3b; Supplementary Table 2). The Taxa70

SVDQuartets bootstrap tree placed Drimiopsis as sister to Resnova + Ledebouria Clade A, but with the lowest bootstrap support of all the nodes (Supplemental Fig. 12). Lastly, SVDQuartets placed Drimiopsis botryoides subsp. botryoides CCH153, the same sample implicated in hybridization (Fig. 3a; Supplementary Fig. 13), within Ledebouria Clade A (Supplemental Figs. $9-12)$

\section{DISCUSSION}

We provide the first phylogenomic insights into the Ledebouriinae. Four major clades were recovered: Ledebouria Clade A, Resnova, Drimiopsis, and Ledebouria Clade B (Figs. 1b, 2, Supplementary Figs. 1 -6). The low number of informative genes coupled with coalescence 


\section{DYNAMICS SHAPING THE EVOLUTION OF THE LEDEBOURIINAE}

180

181

182

183

184

185

186

187

188

189

190

191

192

193

194

195

196

197

198

199

200

201

202

and concordance analyses suggest that incomplete lineage sorting due to rapid radiations may

have played a significant role in the group's evolutionary history. Additionally, historical

hybridization may be contributing to substantial phylogenetic discordance within the group,

particularly within a subclade of Ledebouria Clade A (Fig. 3). Past phylogenetic studies of the

Ledebouriinae have recovered conflicting signal or low resolution along the backbone of the

group (Manning et al. 2003; Pfosser et al. 2003; Lebatha et al. 2006; Wetschnig et al. 2007;

Pfosser 2012). The focus of these studies has largely been on whether Drimiopsis and Resnova

constitute two distinct taxa or are deeply nested within Ledebouria (Manning et al. 2003;

Lebatha et al. 2006; Manning and Goldblatt 2012). Our findings suggest that delimitation of

Drimiopsis and Resnova has been a misguided focus since both have easily distinguishing

characteristics, such as tepal shape, stamen positioning, and non-stipitate ovaries (Lebatha 2004;

Lebatha et al. 2006). Perhaps a more appropriate goal is to uncover diversity within Ledebouria, and we recommend attention should now shift to delimiting and interpreting the history of its two independent lineages. Reconfiguring both the broad- and fine-scale taxonomy of the Ledebouriinae is beyond the scope of this work, but our results lead us to question the status of Ledebouria sensu Manning (2003).

The current geographic distribution of the Ledebouriinae is reflected within the phylogeny and provides clues as to potential historical factors that have shaped their evolution. For example, the two Ledebouria clades overlap geographically in eastern Africa, which now serves as a melting pot, center of diversity, area of endemism, and biogeographical hub for many different African plants and animals (Lebatha 2004; Zhou et al. 2011; Lorenzen et al. 2012;

Dagallier et al. 2020). Similar influences may have also shaped the current diversity and distribution of Drimiopsis, which, based on our limited sampling, consist of two clades: a South 


\section{Howard, et al.}

203

204

205

206

207

208

209

210

211

212

213

214

215

216

217

218

219

220

221

222

223

224

225

African clade, and a northern African clade (Fig. 1). These Drimiopsis clades are distinguishable by morphological traits and different ploidy level (Stedje and Nordal 1987; Lebatha 2004). Surprisingly, SVDQuartets consistently, albeit with low support, placed the East African Drimiopsis botryoides subsp. botryoides (CCH153) within Ledebouria Clade A. Our SNaQ analyses implicate this taxon in a potential hybridization event involving an ancestral taxon within Ledebouria Clade A (Fig. 3a; Supplementary Fig. 12), and 15 gene trees support its placement within this subclade and a further 48 gene trees weakly reject its placement in the subclade (Fig. 3b; Supplementary Table 2). Today, sympatric populations of all Ledebouriinae can be found in sub-Saharan Africa, with the highest sympatry in eastern South Africa (Venter 1993; Lebatha 2004). Therefore, it is not unreasonable to hypothesize that ancestral populations of some Drimiopsis and Ledebouria Clade A may have overlapped in distribution leading to potential hybridization. East African Drimiopsis are known polyploids (Stedje and Nordal 1987), which lead us to suspect that hybridization may be at play in these lineages. However, more extensive sampling of Drimiopsis is needed to fully test any hypotheses regarding historical hybridization within the Ledebouriinae.

Ledebouriinae taxa are continually being described (Hankey et al. 2014; Cumming 2018; Hankey 2020), and much remains to be uncovered about their diversity (Howard 2014). This is exemplified by Ledebouria sp. 1 Mozambique, whose placement has 1) low support in the IQTree and ASTRAL trees (Fig. 2), 2) has different placement in the IQ-Tree and SVDQuartet trees (Fig. 2a, Supplementary Figs. 9 - 10), 3) has the lowest quartet fidelity value (i.e., a measure for rogue taxa) of all the tips (Taxa70 dataset; Supplementary Fig. 14), 4) is found sister to the Ledebouriinae in several gene trees (Fig. 3b; Supplementary Table 2), and 5) exhibits unique morphological characteristics compared to currently known Ledebouriinae (e.g., seeds 


\section{DYNAMICS SHAPING THE EVOLUTION OF THE LEDEBOURIINAE}

226

227

228

229

230

231

232

233

234

235

236

237

238

239

240

241

242

243

244

245

246

247

possess a rostrate hilum giving them a distinctive pointed appearance; Supplementary Fig. 15).

Whether this sample represents a distinct lineage remains to be understood.

Our results showcase the value of extending the phylogenomic repertoire to groups with unexplored potential. Our use of the Angiosperms353 probe set was vital for uncovering a revealing Ledebouriinae phylogeny, but a custom probe set may prove even more informative.

Our analyses suggest that gene tree conflict due to incomplete lineage sorting and hybridization is prevalent within the phylogeny (Table 1; Fig. 3), and several short backbone branches suggest rapid radiations (Fig. 2). Increasing Ledebouria samples from Central and West Africa as well as significantly improving sampling of Resnova and Drimiopsis will be necessary to fully capture the intricate genomic evolution of the group. The role that incomplete lineage sorting and hybridization have played in historically obscuring the evolutionary history of the Ledebouriinae present an exciting opportunity for further study.

\section{FUNDING}

This work was supported by funds from the Huntington Botanical Gardens; the Cactus and Succulent Society of America; the Pacific Bulb Society (Mary Sue Ittner Bulb Research Grant); the San Gabriel Cactus and Succulent Society; the Florida Museum of Natural History; the American Society of Plant Taxonomists; the University of Florida International Center; the University of Florida Department of Biology; the Botanical Society of America; the Society of Systematic Biologists; Xeric Growers; and numerous private donors. 


\section{Howard, et al.}

248 We are extremely grateful to Leevi Nanyeni, Silke Rügheimer and Dr. Esmeralda Klassen at the

249 National Botanical Research Institute in Windhoek, Namibia for their assistance with fieldwork 250 and specimen export while in Namibia; Inge Pehlemann for enjoyable Namibian excursions in

251 search of Ledebouria and others plants; Dr. David Chuba at the University of Zambia with

252 assistance in acquiring collection and export permits for Zambia; Dr. Neduvoto Mollel at the

253 Tropical Pesticides Research Institute in Arusha, Tanzania for help in obtaining collection and

254 export permits for Tanzania. Sincere thanks to the governments of Namibia, Zambia, and

255 Tanzania for issuing collection and export permits. Collections from Namibia were made under

256 permit numbers 1784/2013, 1908/2014, 2056/2016, and 2185/2016. Zambian collections were

257 made under permit number TJ/DNPW/101/13/18. Tanzanian collections were made under permit

258 number 2017-22-NA-2016-247. Living plants were imported under USDA permit numbers P37-

259 09-00910, P37-16-00181, and P37-16-01462. We also express our deep gratitude to Dylan

260 Hannon, Gottfriend Milkuhn, Tom Cole, and Tom McCoy for donating leaf material from

261 geographically crucial taxa.

262

\section{DISCLOSURE STATEMENT}

264 The authors have no conflict of interests to disclose.

267 The raw genomic reads for each sample used in this study are available on the SRA (BioProject

268 ID: PRJNA721471). Supplementary Methods, Results, and Figures as well as alignment files,

269 individual gene trees, and output files for each analysis are available on Dryad (DOI: upon

270 acceptance). 


\section{DYNAMICS SHAPING THE EVOLUTION OF THE LEDEBOURIINAE}

\section{LITERATURE CITED}

Ali S.S., Pfosser M., Wetschnig W., Martínez-Azorín M., Crespo M.B., Yu Y. 2013. Out of Africa: Miocene dispersal, vicariance, and extinction within Hyacinthaceae subfamily Urgineoideae. J. Integr. Plant Biol. 55:950-964.

Ali S.S., Yu Y., Pfosser M., Wetschnig W. 2012. Inferences of biogeographical histories within subfamily Hyacinthoideae using S-DIVA and Bayesian binary MCMC analysis implemented in RASP (Reconstruct Ancestral State in Phylogenies). Ann. Bot. 109:95107.

Balinsky B.I. 1962. Patterns of animal distribution on the African continent. Ann. Cape Prov. Mus. 2:299-310.

Bobe R. 2006. The evolution of arid ecosystems in eastern Africa. J. Arid Environ. 66:564-584.

Breinholt J.W., Carey S.B., Tiley G.P., Davis E.C., Endara L., McDaniel S.F., Neves L.G., Sessa E.B., von Konrat M., Chantanaorrapint S., Fawcett S., Ickert-Bond S.M., Labiak P.H., Larraín J., Lehnert M., Lewis L.R., Nagalingum N.S., Patel N., Rensing S.A., Testo W., Vasco A., Villarreal J.C., Williams E.W., Burleigh J.G. 2021. A target enrichment probe set for resolving the flagellate land plant tree of life. Appl. Plant Sci. 9:e11406.

Buerki S., Jose S., Yadav S.R., Goldblatt P., Manning J.C., Forest F. 2012. Contrasting biogeographic and diversification patterns in two Mediterranean-type ecosystems. PLoS One. 7:e39377.

Chifman J., Kubatko L. 2014. Quartet inference from SNP data under the coalescent model. Bioinformatics. 30:3317-3324.

Couvreur T.L.P., Dauby G., Blach-Overgaard A., Deblauwe V., Dessein S., Droissart V., Hardy O.J., Harris D.J., Janssens S.B., Ley A.C., Mackinder B.A., Sonké B., Sosef M.S.M., Stévart T., Svenning J.-C., Wieringa J.J., Faye A., Missoup A.D., Tolley K.A., Nicolas V., Ntie S., Fluteau F., Robin C., Guillocheau F., Barboni D., Sepulchre P. 2020. Tectonics, climate and the diversification of the tropical African terrestrial flora and fauna. Biol. Rev. Camb. Philos. Soc.

Cumming D.M. 2018. Two New Species of Ledebouria from the Eastern Cape. Cactus and Succulent Journal. 90:119-125.

Dagallier L.-P.M.J., Janssens S.B., Dauby G., Blach-Overgaard A., Mackinder B.A., Droissart V., Svenning J.-C., Sosef M.S.M., Stévart T., Harris D.J., Sonké B., Wieringa J.J., Hardy O.J., Couvreur T.L.P. 2020. Cradles and museums of generic plant diversity across tropical Africa. New Phytol. 225:2196-2213.

Dodsworth S., Pokorny L., Johnson M.G., Kim J.T., Maurin O., Wickett N.J., Forest F., Baker W.J. 2019. Hyb-Seq for Flowering Plant Systematics. Trends Plant Sci. 24:887-891.

Giranje P.T., Nandikar M.D. 2016. Synopsis of the genus Ledebouria Roth (Hyacinthaceae: Hyacinthoideae) in India. Webbia. 71:213-217.

Goldblatt P., Manning J.C., Forest F. 2012. A review of chromosome cytology in Hyacinthaceae subfamilies Urgineoideae and Hyacinthoideae (tribes Hyacintheae, Massonieae, Pseudoprospereae) in sub-Saharan Africa. South African Journal of Botany. 83:134-144. Hankey A. 2020. Ledebouria loskopica a New Endemic Species from Loskop Dam Nature Reserve, Mpumalanga, South Africa. Cactus and Succulent Journal. 92:118-122. 
Howard, et al.

Hankey A.J., Hahn N., Buys M.H. 2014. Ledebouria caesiomontana AJ Hankey \& N. Hahn (Hyacinthaceae: Hyacinthoideae): a new species from the Blouberg centre of endemism, Limpopo, South Africa. Bothalia-African Biodiversity \& Conservation. 44:1-4.

Howard C.C., Folk R.A., Beaulieu J.M., Cellinese N. 2019. The monocotyledonous underground: global climatic and phylogenetic patterns of geophyte diversity. Am. J. Bot. 106:850-863.

Howard C.C. 2014. In the shade of the mopane: Ledebouria in Namibia. Cactus and Succulent Journal. 86:92-98.

Jacobs B.F. 2004. Palaeobotanical studies from tropical Africa: relevance to the evolution of forest, woodland and savannah biomes. Philos. Trans. R. Soc. Lond. B, Biol. Sci. 359:1573-1583.

Jang T.-S., Parker J.S., Emadzade K., Temsch E.M., Leitch A.R., Weiss-Schneeweiss H. 2018. Multiple origins and nested cycles of hybridization result in high tetraploid diversity in the monocot Prospero. Front. Plant Sci. 9:433.

Johnson M.G., Pokorny L., Dodsworth S., Botigué L.R., Cowan R.S., Devault A., Eiserhardt W.L., Epitawalage N., Forest F., Kim J.T., Leebens-Mack J.H., Leitch I.J., Maurin O., Soltis D.E., Soltis P.S., Wong G.K.-S., Baker W.J., Wickett N.J. 2019. A Universal Probe Set for Targeted Sequencing of 353 Nuclear Genes from Any Flowering Plant Designed Using k-Medoids Clustering. Syst. Biol. 68:594-606.

Johnson S.D., Pauw A., Midgley J. 2001. Rodent pollination in the African lily Massonia depressa (Hyacinthaceae). Am. J. Bot. 88:1768-1773.

Larridon I., Villaverde T., Zuntini A.R., Pokorny L., Brewer G.E., Epitawalage N., Fairlie I., Hahn M., Kim J., Maguilla E., Maurin O., Xanthos M., Hipp A.L., Forest F., Baker W.J. 2019. Tackling rapid radiations with targeted sequencing. Front. Plant Sci. 10:1655.

Lebatha P., Buys M.H., Stedje B. 2006. Ledebouria, Resnova and Drimiopsis: a tale of three genera. Taxon. 55:643-652.

Lebatha P.D. 2004. A systematic revision of Drimiopsis Lindl. \& Paxt. (Hyacinthaceae). .

Linder H.P. 2014. The evolution of African plant diversity. Front. Ecol. Evol. 2:1-14.

Lorenzen E.D., Heller R., Siegismund H.R. 2012. Comparative phylogeography of African savannah ungulates. Mol. Ecol. 21:3656-3670.

Manning J.C., Goldblatt P., Fay M.F. 2003. A revised generic synopsis of Hyacinthaceae in subSaharan Africa, based on molecular evidence, including new combinations and the new tribe Pseudoprospereae. Edin. Jnl of Bot. 60:533-568.

Manning J.C., Goldblatt P. 2012. New combinations in Ledebouria. Bothalia. 42:47-48.

Manning J.C. 2020. Systematics of Ledebouria sect. Resnova (Hyacinthaceae: Scilloideae: Massonieae), with a new subtribal classification of Massonieae. South African Journal of Botany. 133:98-110.

Martínez-Azorín M., Crespo M.B., Juan A., Fay M.F. 2011. Molecular phylogenetics of subfamily Ornithogaloideae (Hyacinthaceae) based on nuclear and plastid DNA regions, including a new taxonomic arrangement. Ann. Bot. 107:1-37.

Minh B.Q., Hahn M.W., Lanfear R. 2020. New methods to calculate concordance factors for phylogenomic datasets. Mol. Biol. Evol. 37:2727-2733.

Müller-Doblies U., Müller-Doblies D. 2008. A partial revision of the tribe Massonieae (Hyacinthaceae) 1. Survey, including three novelties from Namibia: A new genus, a second species in the monotypic Whiteheadia, and a new combination in Massonia. Feddes Repert. 108:49-96. 


\section{DYNAMICS SHAPING THE EVOLUTION OF THE LEDEBOURIINAE}

401

402

403

404

405

Partridge T.C., Maud R.R. 1987. Geomorphic evolution of southern Africa since the Mesozoic. South African Journal of Geology. 90:179-208.

Pease J.B., Brown J.W., Walker J.F., Hinchliff C.E., Smith S.A. 2018. Quartet Sampling distinguishes lack of support from conflicting support in the green plant tree of life. Am. J. Bot. 105:385-403.

Pfosser M., Wetschnig W., Ungar S., Prenner G. 2003. Phylogenetic relationships among genera of Massonieae (Hyacinthaceae) inferred from plastid DNA and seed morphology. J Plant Res. 116:115-132.

Pfosser M. 2012. Phylogenetic relationships of Malagasy Hyacinthaceae. Plant Ecol. Evol. 145:65-72.

Pokorny L., Riina R., Mairal M., Meseguer A.S., Culshaw V., Cendoya J., Serrano M., Carbajal R., Ortiz S., Heuertz M., Sanmartín I. 2015. Living on the edge: timing of Rand Flora disjunctions congruent with ongoing aridification in Africa. Front. Genet. 6:154.

Sayyari E., Whitfield J.B., Mirarab S. 2018. DiscoVista: Interpretable visualizations of gene tree discordance. Mol. Phylogenet. Evol. 122:110-115.

Solís-Lemus C., Bastide P., Ané C. 2017. Phylonetworks: A package for phylogenetic networks. Mol. Biol. Evol. 34:3292-3298.

Speta F. 1998. Hyacinthaceae. Flowering Plants: Monocotyledons.261-285.

Stedje B., Nordal I. 1987. Cytogeographical studies of Hyacinthaceae in Africa south of the Sahara. Nordic journal of botany. 7:53-65.

Steele P.R., Hertweck K.L., Mayfield D., McKain M.R., Leebens-Mack J., Pires J.C. 2012. Quality and quantity of data recovered from massively parallel sequencing: Examples in Asparagales and Poaceae. Am. J. Bot. 99:330-348.

Swofford D.L. 2001. Paup*: Phylogenetic analysis using parsimony (and other methods). Citeseer.

The Angiosperm Phylogeny Group. 2016. An update of the Angiosperm Phylogeny Group classification for the orders and families of flowering plants: APG IV. Botan J Linn Soc. 181:1-20.

The Plant List. 2013. The Plant List. Available from http://www.theplantlist.org.

Venter S. 1993. A revision of the genus Ledebouria Roth (Hyacinthaceae) in South Africa. .

Vogel S., Müller-Doblies U. 2011. Desert geophytes under dew and fog: The "curly-whirlies" of Namaqualand (South Africa). Flora-Morphology, Distribution, Functional Ecology of Plants. 206:3-31.

Wetschnig W., Knirsch W., Ali S.S., Pfosser M. 2007. Systematic position of three little known and frequently misplaced species of Hyacinthaceae from Madagascar. PHYTON-HORN. 47:321.

Zhang C., Rabiee M., Sayyari E., Mirarab S. 2018. ASTRAL-III: polynomial time species tree reconstruction from partially resolved gene trees. BMC Bioinformatics. 19:153.

Zhou L., Su Y.C.F., Thomas D.C., Saunders R.M.K. 2011. 'Out-of-Africa' dispersal of tropical floras during the Miocene climatic optimum: evidence from Uvaria (Annonaceae). J. Biogeogr. 39:322-335. 


\section{Howard, et al.}

406

407

408

409

410

411

412

413

414

415

416

\section{SUPPLEMENTARY FIGURES}

418 Supplementary Figure 1. Maximum likelihood phylogenetic reconstruction using IQ-Tree of the 419 full dataset. Branch labels show SH-aLRT support value/Ultrafast bootstrap support value/gene 420 concordance factor/site concordance factor. Strong support is branches with SH-aLRT and

421 UFBoot values above 80 and 95, respectively.

422

423 Supplementary Figure 2. Species tree estimation of the full dataset inferred from ASTRAL.

424 Branch labels indicate local posterior probability (LPP) support values.

426 Supplementary Figure 3. Maximum likelihood phylogenetic reconstruction using IQ-Tree of the

427 Taxa70 dataset. Branch labels show SH-aLRT support value/Ultrafast bootstrap support 


\section{DYNAMICS SHAPING THE EVOLUTION OF THE LEDEBOURIINAE}

428 value/gene concordance factor/site concordance factor. Strong support is branches with SH-

429 aLRT and UFBoot values above 80 and 95, respectively.

431 Supplementary Figure 4. Species tree estimation of the Taxa70 dataset inferred from ASTRAL.

432 Branch labels indicate local posterior probability (LPP) support values.

434 Supplementary Figure 5. Maximum likelihood phylogenetic reconstruction using IQ-Tree of the

435 Taxa70 dataset with Ledebouria sp. 1 Mozambique removed from the analysis. Branch labels

436 show SH-aLRT support value/Ultrafast bootstrap support value/gene concordance factor/site

437 concordance factor. Strong support is branches with SH-aLRT and UFBoot values above 80 and

43895 , respectively.

439

440 Supplementary Figure 6. Species tree estimation of the Taxa70 dataset with Ledebouria sp. 1

441 Mozambique removed inferred from ASTRAL. Branch labels indicate local posterior probability

442 (LPP) support values.

443

444 Supplementary Figure 7. Maximum likelihood phylogeny with quartet sampling values drawn on

445 branches using the full dataset. Values on branches are quartet concordance (QC)/quartet

446 differential (QD)/quartet informativeness (QI).

447

448 Supplementary Figure 8. Maximum likelihood phylogeny with quartet sampling values drawn on

449 branches using the Taxa70 dataset. Values on branches are quartet concordance (QC)/quartet

450 differential (QD)/quartet informativeness (QI). 
Howard, et al.

452 Supplementary Figure 9. Species tree estimation of the full dataset using singular value

453 decomposition quartet species-tree estimation (SVDQuartets). Phylogeny was reconstructed

454 using an exhaustive search.

455

456 Supplementary Figure 10. Species tree estimation of the full dataset using singular value

457 decomposition quartet species-tree estimation (SVDQuartets). Phylogeny was reconstructed

458 using an exhaustive search. Branch labels indicate bootstrap support from 100 bootstrap

459 replicates.

Supplementary Figure 11. Species tree estimation of the Taxa70 dataset using singular value 462 decomposition quartet species-tree estimation (SVDQuartets).

464 Supplementary Figure 12. Species tree estimation of the Taxa70 dataset using singular value 465 decomposition quartet species-tree estimation (SVDQuartets). Phylogeny was reconstructed 466 using an exhaustive search. Branch labels indicate bootstrap support from 100 bootstrap 467 replicates.

469 Supplementary Figure 13. SNaQ results from ten randomly sampled subsets of the

470 Ledebouriinae phylogeny. Network 1 reports results from analyses that allowed 1 hybrid edge $471(\mathrm{~h}=1)$, and network 2 reports results from analyses that allowed up to 2 hybrid edges $(\mathrm{h}=2)$ for 472 each replicate. Dark blue lines indicate the major hybrid edge, light blue lines indicate the minor 


\section{DYNAMICS SHAPING THE EVOLUTION OF THE LEDEBOURIINAE}

473 edge. Inheritance probabilities are provided on the edges. Gray lines connect branches that are

474 rotated across the two phylogenies.

475

476 Supplementary Figure 14. Maximum likelihood phylogeny showing quartet fidelity (QF) values

477 for each of the samples in the Taxa70 dataset. Values represent a measure of taxon "rogueness",

478 that is, a measure of how much a tip jumps around a phylogeny.

479

480 Supplementary Figure 15. Ledebouria sp. 1 Mozambique (a) showing the pronounced rostrate

481 hilum that sets it apart from other Ledebouriinae (e.g., image b) that typically have more

482 spherical seeds.

483 